\title{
Effects of Gas Metal Arc Welding Techniques on the Mechanical Properties of Duplex Stainless Steel
}

\author{
Tanimu Ibrahim ${ }^{1}$, Danjuma S. Yawas ${ }^{2}$, Shekarau Y. Aku ${ }^{2}$ \\ ${ }^{1}$ Plant and Equipment Department, Salini Nigeria Limited, Abuja, Nigeria \\ ${ }^{2}$ Mechanical Engineering Department, Ahmadu Bello University, Zaria, Nigeria \\ Email: terrytanimu@yahoo.com
}

Received July 5, 2013; revised August 9, 2013; accepted August 22, 2013

Copyright (C) 2013 Tanimu Ibrahim et al. This is an open access article distributed under the Creative Commons Attribution License, which permits unrestricted use, distribution, and reproduction in any medium, provided the original work is properly cited.

\begin{abstract}
The study has compared the effect of gas metal arc welding techniques on some mechanical properties of duplex stainless steel. The samples after welded were given post weld heat treatment (quenching in engine and neem oil). After the analyses, it was established that duplex stainless steel can be weld successfully using gas metal arc welding process (GMAW). Both Lubricating oil and neem oil can serve as quenching medium for post welding heat treatment of duplex stainless steel. The results of the studies also show that welding and heat treatment really affect the mechanical properties of the alloy; the control strength was $811.47 \mathrm{MN} / \mathrm{m}^{2}$ while that of the welded samples ranged from 177.07 to 257.32 $\mathrm{MN} / \mathrm{m}^{2}$. The control impact energy was $162.70 \mathrm{~J}$, while that of the welded samples ranged from $38.64 \mathrm{~J}$ to $56.20 \mathrm{~J}$. The research also shows that the stress relief heat treatment gives better strength $\left(A_{3}=331 \mathrm{MN} / \mathrm{m}^{2}\right)$ compared to those that were quenched in lubricating oil $\left(\mathrm{A}_{2}=329 \mathrm{MN} / \mathrm{m}^{2}\right)$ and neem oil $\left(\mathrm{A}_{1}=222 \mathrm{MN} / \mathrm{m}^{2}\right)$, but the reverse is the case in terms of toughness.
\end{abstract}

Keywords: Duplex Stainless Steel; Welding Techniques; Tensile Strength; Hardness Number; Impact Energy; Heat Treatment

\section{Introduction}

A large number of failures in industries are either directly or indirectly attributed to welds because of the inhomogeneity within the weldment, stress concentration, residual stress, inclusion of impurities etc. which invariably make it the weakest region [1]. However a vast majority of repairs of failed components in industries are carried out using one of the welding processes and the success depends on many factors such as weldability of the material, type of damage, availability of suitable welding technique, possibility of carrying out pre-heating or post weld heat treatment, post repair inspection by non-destructive testing (NDT) techniques [1].

Duplex stainless steels are two phase alloys based on the iron-chromium-nickel system. These alloys usually comprise of equal proportions of the body centered cubic (BCC) ferrite and face centered cubic (FCC) austenite phase in their microstructure and generally have low carbon content as well as additions of molybdenum, nitrogen, tungsten, and copper. Typical chromium contents range from $20 \%$ to $30 \%$ by weight, nickel ranges from $5 \%$ to $10 \%$ by weight [2].
Duplex stainless steels solidify as $100 \%$ ferrite, but about half of the ferrite transforms to austenite during cooling through temperatures above $1040^{\circ} \mathrm{C}$. This behavior is accomplished by increasing $\mathrm{Cr}$ and decreasing $\mathrm{Ni}$ content as compared to the austenitic grades [2].

Duplex stainless steels are ferromagnetic, a property that can easily differentiate them from common austenitic grades of stainless steels. Generally the ratio of ferrite to austenite in duplex stainless steels depends mainly on the chemical composition. The presence of ferrite with austenite provides better intergranular corrosion (IGC) resistance, other advantages offered by these alloys over convection 300 series stainless steels are strength, chloride stress-corrosion cracking resistance, and pitting corrosion resistance [2].

Duplex stainless steels are increasingly used as structural materials in building and architecture because of their exceptional mechanical properties. Their room temperature yield strength in the solution annealed condition is more than twice that of standard austenitic stainless steels not alloyed with nitrogen. Over the last few years, they have started playing an increasingly important role in the construction of bridges, wherever specific envi- 
ronmental conditions combine with the need for high load-bearing capability. Duplex stainless steels are mostly selected because of their combination of high strength and corrosion resistance. Their full potential is used in locations where the material comes into contact with salt water or where high concentrations of chlorides are present in the ambient air or where de-icing salts are of a concern.

With all their afore-mentioned favorable properties, the duplex stainless steels still fail mostly at the weld points which can be as a result of the welding process, process variables used and the welding environmental contamination. Hence, this research work is targeted to verify the effect of welding process and heat treatment on the mechanical properties of duplex stainless steels. The mechanical properties that are to be investigated are; tensile strength, impact strength and hardness, as we already know that the durability of a welded structure directly depends on the resulting mechanical properties after welding. This work will also look at the effect of stress relief, full annealing, normalizing, and hardening heat treatment methods on the mechanical properties of duplex stainless steel.

\section{Materials and Method}

\subsection{Materials}

Duplex stainless steel was the main material used for this research work which was sourced locally at Jos building materials market in Nigeria, while its chemical composition was determined at National Metallurgical Center Jos using the XFR test. Other materials that were used are: lubricating oil 85W90, neem oil, Nertalic 50 wire elec- trode, and etchant.

\subsection{Methodology}

\subsubsection{Pre-Welding Sample Preparation}

The duplex stainless steel rod was cut into equal pieces (samples) of length $100.2 \mathrm{~mm}$; they were further cut into two equal parts then joined together using gas metal arc welding process and subjected to different treatments, while some samples served as standards for comparison and analysis.

All the samples for welding were each chamfered to produce $30^{\circ}$ half groove angle on one side with the aid of a milling machine, leaving a root face of $2 \mathrm{~mm}$ each. The butt joint welding method was implemented as illustrated in Figure 1.

Samples were cleaned of dirt and oil and a grinding machine was used to grind the surfaces of samples prior to welding in order to have smooth and uniform surfaces according to Dauda [3].

\subsubsection{Welding Procedure}

The gas metal arc welding process was used to weld over one hundred samples respectively. They were laid on an angle bar with their beveled edges parallel and facing each other, leaving a root face and root opening of $2 \mathrm{~mm}$ with an included angle of $60^{\circ}$ then an arc was struck. The first bead was laid down at the root of the joint to ensure equal fusion in both rods, before the second bead was laid the first bead was allowed to cool down to about $150^{\circ} \mathrm{C}$. In case of any slag noticed was removed before an additional bead was laid. The welding parameters are shown in Table 1. The number of passes used was two

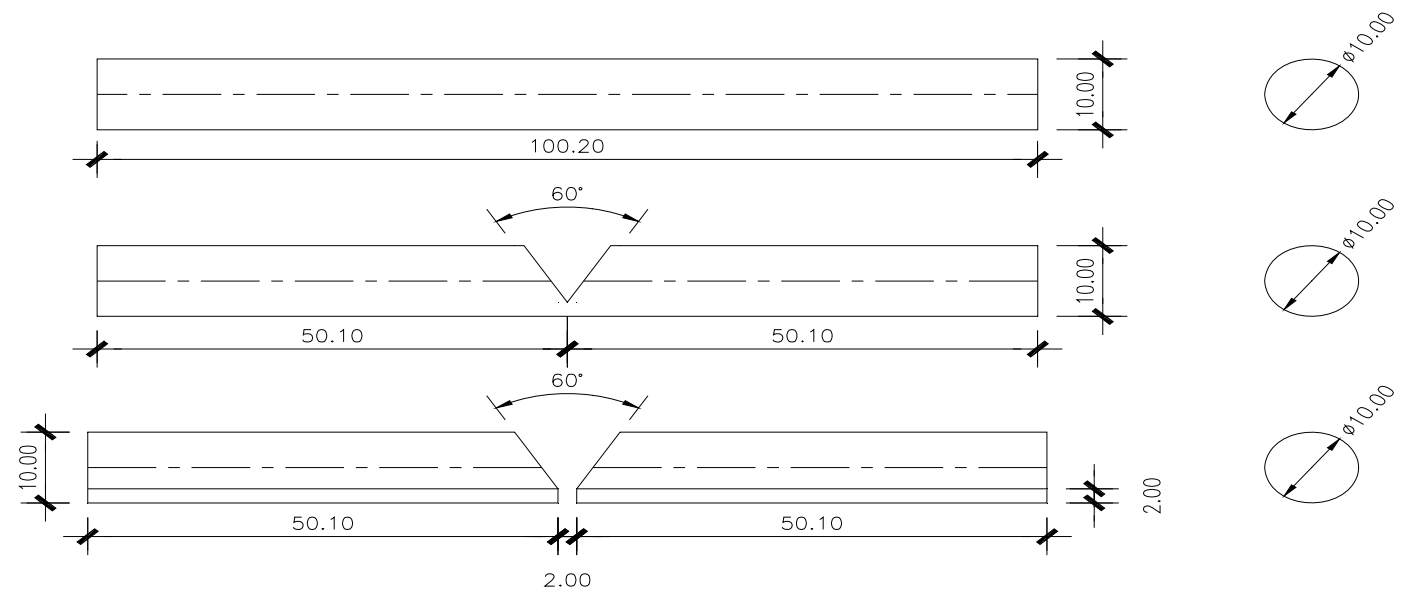

Figure 1. Joint preparation for V-groove welding [2].

Table 1. Welding parameter.

\begin{tabular}{cccccccc}
\hline Type of welding & Electrode type & Diameter & Transfer mode & Current & Voltage & Polarity & Shielding gas \\
\hline GMAW & Nertalic 50 & $1.6 \mathrm{~mm}$ & Spray & $200 \mathrm{~A}$ & $26 \mathrm{~V}$ & DCEP & Argon \\
\hline
\end{tabular}


on each of the sample; the second pass was to fill the grove and to produce a crown.

Both welded samples were cleaned of dirt and oil. The grinding machine was used to grind the surfaces of samples after welding in order to have smooth and uniform surfaces.

\subsubsection{Post-Welding Thermal Treatment}

Two post thermal heat treatments were adopted viz:

1) Stress relieves annealing.

2) Hardening by quenching.

\section{Stress-Relieve Annealing}

This treatment was done by heating the samples from ambient temperature up to $600^{\circ} \mathrm{C}$, and then soaked at this temperature for 30 minutes. After which they were removed from the furnace and air cooled back to ambient temperature.

\section{Quenching and Tempering}

Samples, that had been previously stress relieved were again heated to the temperature of $900^{\circ} \mathrm{C}$ and remained at this temperature for 30 minutes, they were then quickly removed and plunged into a can of engine oil or Neem oil at room temperature. The quenched samples were tempered slowly by reheating them to $300^{\circ} \mathrm{C}$ and allowed to soak for 30 minutes, after which they were removed from the furnace and allowed to cool to room temperature in air.

\subsubsection{Mechanical Test Procedure Tensile Strength Test}

Tensile strength indicates the ability of a composite material to withstand forces that pull it apart as well as the capability of the material to stretch prior to failure. Tensile tests were carried out using a Hounsfield Tensiometer, with maximum load of $250 \mathrm{KN}$. The standard samples were mounted by their ends into the holding grips of the testing apparatus.

The machine is designed to elongate the sample at a constant rate, and to measure the instantaneous applied load and the resulting elongations simultaneously using an extensometer. Samples were prepared as shown in Figure 2 according to BS18 standard.

Proportional sample (BS18) are given by the relationship $\mathrm{L}_{\mathrm{O}}=5.56 \sqrt{\mathrm{A}}$. Since $\mathrm{A}=\pi \mathrm{d}^{2} / 4$, then $\sqrt{\mathrm{A}}=\mathrm{d} \sqrt{\pi} / 2=0.88 \mathrm{~d}$. Thus $\mathrm{L}_{\mathrm{O}}=5.65 \times 0.88 \mathrm{~d} \approx 5 \mathrm{~d}$, [4].

\section{Charpy Impact Test}

Charpy Impact tests were conducted in accordance with ASTM A370 "Standard Methods and Definitions for Mechanical Testing of Steel Products", and ASTM E23, "Standard Method for Notched Bar Impact Testing of Metallic Materials". The Charpy V-notch samples, used in this evaluation, were machined according to the specification in ASTM E23 as shown in Figure 3.

\section{Hardness Test}

The hardness values of the samples were determined

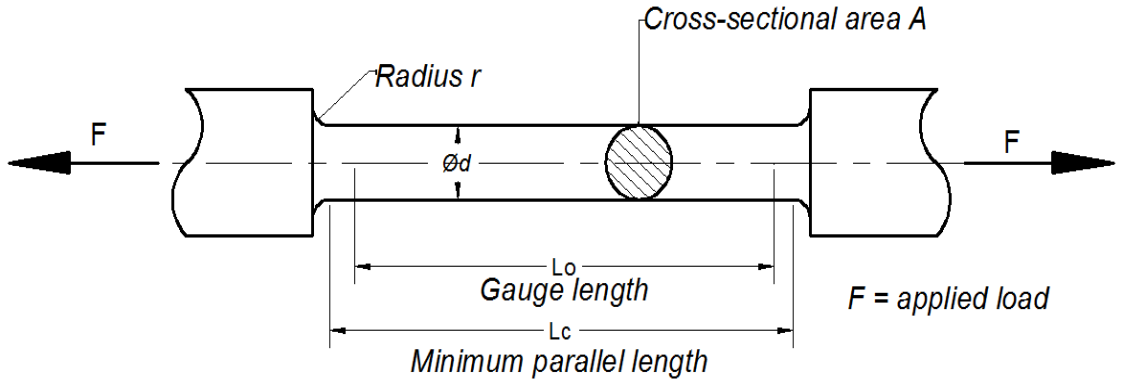

Figure 2. Standard sample for tensile test [24]. Proportional samples (BS18) are given by the relationship. $L_{0}=5.56 \sqrt{A}$. Since $\mathrm{A}=\pi \mathrm{d}^{2} / 4$, then $\sqrt{\mathrm{A}}=\mathrm{d} \sqrt{\pi} / 2=0.88 \mathrm{~d}$. Thus $\mathrm{L}_{\mathrm{O}}=5.65 \times 0.88 \mathrm{~d} \approx 5 \mathrm{~d}[24]$.
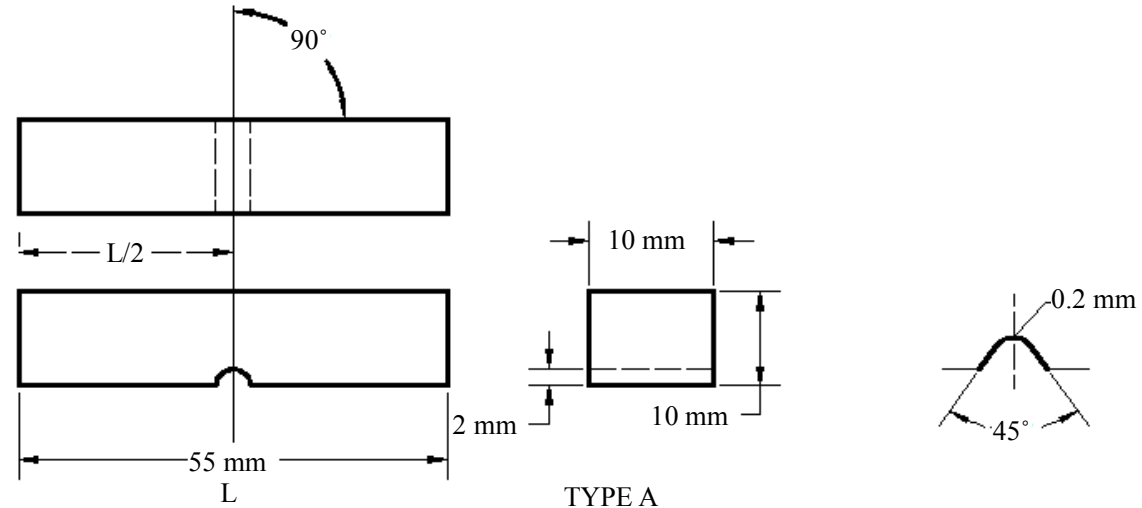

Figure 3. Standard sample for charpy impact test. 
according to the provisions in ASTM E18 - 79 using the Rockwell hardness tester with a $1.56 \mathrm{~mm}$ steel ball indenter, minor load of $10 \mathrm{Kg}$, and major load of $150 \mathrm{Kg}$ and harness value of $56.4 \mathrm{HRC}$ as a standard block. Before the test, the mating surface of the indenter, plunger rod and the test samples were thoroughly cleaned by removing the dirt, scratches and oil.

\subsubsection{Microstructural Analysis Surface Preparation}

The surfaces of samples for metallographic examination were ground and polished. The grinding process was performed using silicon carbide papers of varying grits starting with the coarsest grit size of 120 . Subsequently grit size of 240, 320, 400 and 600 were used. The grinding was done wet with the aid of a lubricant. The lubricant were applied intermittently to prevent overheating of the sample and to provide a rinsing action to flush away the particles being removed from the surface.

Polishing was carried out using a silicon abrasive in form of a very fine powder (1000 grit). The powder was applied to a wet polishing wheel rotating in the clockwise direction. The samples were polished by rotating them in the direction opposite to the direction of rotation of the wheel. This resulted into a shiny, scratch free surface ready for etching and microscopy.

\section{Etching}

Etching was done to expose and make visible the grains of the samples structural characteristics of the sample under the different conditions of heat treatment, as received and as welded. The etching was done using $10 \mathrm{cc}$ of $\mathrm{HCl}, 3 \mathrm{cc} \mathrm{HNO}_{3}$ and $100 \mathrm{cc}$ distilled water.

Scanning Electron Microscope Analysis

Samples after preparation were attached to multi-stub sample holder with the use of double sided conductive aluminum tape, after which, they were mounted onto the sample chamber, while the column was put at vacuum. After reaching the vacuum target, the electron gun was switched on which passed an accelerating voltage of 20 $\mathrm{kV}$ and probe current of $227 \mathrm{pA}$ through the samples at a working distance of $7.0 \mathrm{~mm}$ and $6.0 \mathrm{~mm}$.

Micrographs of the Samples were taken at two different positions viz; the fusion Zone (FZ) and the heat affected Zone (HAZ). The scanning electron microscope (SEM) EVO MA-10 manufactured by Carl, was used for the analysis at Sheda Science and Technology Complex, Abuja Nigeria.

\subsubsection{Samples Labeling}

The samples after preparation were labeled as follows before testing them (Table 2); this is also referred to the the discussion of results.

\section{Results and Discussion}

\subsection{Chemical Composition of Research Material}

X-ray florescence test was used to determine the actual chemical composition of the research material. Table 3 below shows the results of XRF test carried out on the material as received from the manufacturing company.

The results of the research material chemical composition as shown on Table 3, prove that the material is actually a duplex stainless steel. This is due to the presence of high percentage composition of iron (Fe) as the base material, chromium $(\mathrm{Cr})$ and manganese $(\mathrm{Mn})$ as major alloying elements, low percentage of Carbon (C) and other trace elements. This is in close agreement with the

Table 2. Samples labeling.

\begin{tabular}{cc}
\hline Sample A & Sample that was welded with GMAW method \\
\hline Sample $\mathrm{A}_{1}$ & Sample that was welded with GMAW and Quenched in NEEM oil (heat treated) \\
Sample $\mathrm{A}_{2}$ & Sample was welded with GMAW and Quenched in Engine oil (heat treated) \\
Sample $\mathrm{A}_{3}$ & Sample that was welded with GMAW and undergo Stress Relief heat treatment \\
Sample C & As received or control \\
\hline
\end{tabular}

Table 3. Research material chemical composition.

\begin{tabular}{|c|c|c|c|c|c|c|c|c|c|}
\hline Element & $\mathrm{C}$ & $\mathrm{Si}$ & $\mathrm{Mn}$ & $\mathrm{P}$ & $\mathrm{S}$ & $\mathrm{Cr}$ & $\mathrm{Ni}$ & Mo & $\mathrm{Al}$ \\
\hline$\%$ by wt & $0.02-0.05$ & 0.238 & 1.57 & 0.036 & 0.032 & $>9.96$ & $>6.60$ & 0.342 & 0.011 \\
\hline Element & V & W & $\mathrm{Pb}$ & B & $\mathrm{Sn}$ & $\mathrm{Zn}$ & As & $\mathrm{Bi}$ & $\mathrm{Ca}$ \\
\hline$\%$ by wt & 0.106 & 0.036 & $>0.003$ & $<0.0005$ & 0.012 & 0.029 & $<0.001$ & 0.009 & 0.0015 \\
\hline Element & $\mathrm{Cu}$ & $\mathrm{Co}$ & $\mathrm{Ti}$ & $\mathrm{Nb}$ & $\mathrm{Ce}$ & $\mathrm{Zr}$ & $\mathrm{La}$ & $\mathrm{Fe}$ & \\
\hline$\%$ by wt & 0.302 & 0.132 & 0.011 & 0.046 & 0.031 & 0.0015 & 0.0043 & 69.6 & \\
\hline
\end{tabular}


chemical composition of Duplex stainless steel grade [5].

\subsection{Scanning Electron Micrograph of the Samples}

The micrographs of the samples, as taken by scanning

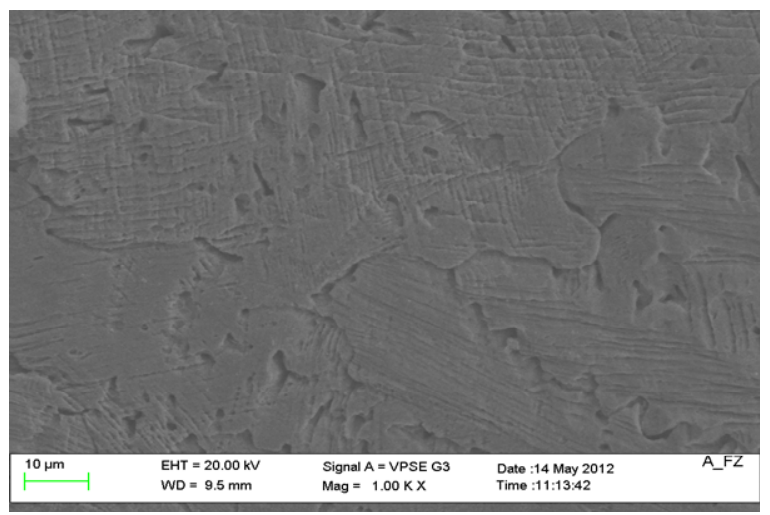

(a)

Figure 4. (a) Micrograph of the fusion zone for sample A; (b) Micrograph of the heat affected zone for sample A.

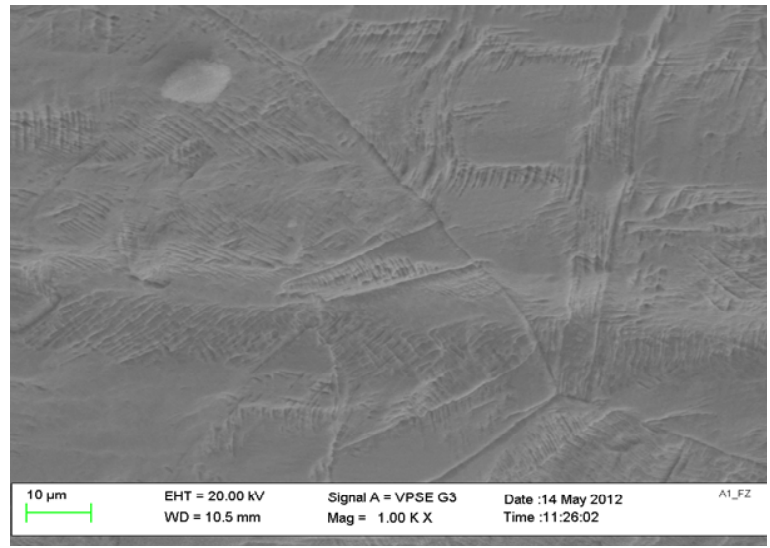

(a) electron microscope, are presented in Figures 4-8.

SEM was used to study the morphology of all the welded and as received samples. Figure 8 shows the SEM micrograph of as received sample. Figures 4-7 show the SEM micrograph of the group A samples.

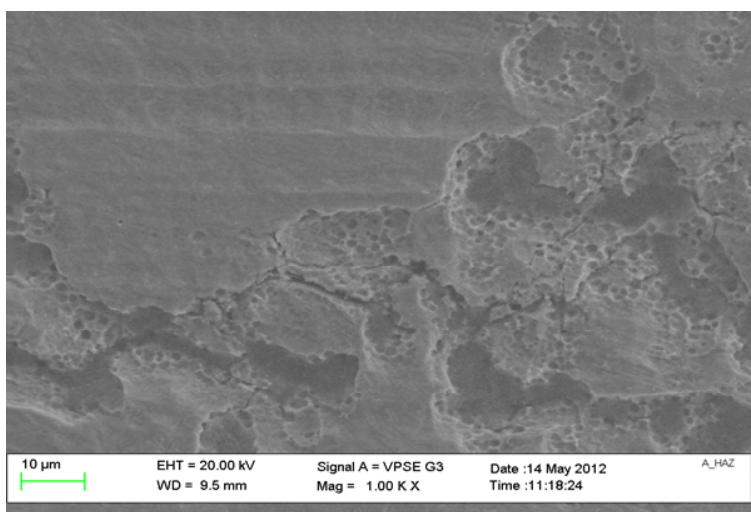

(b)

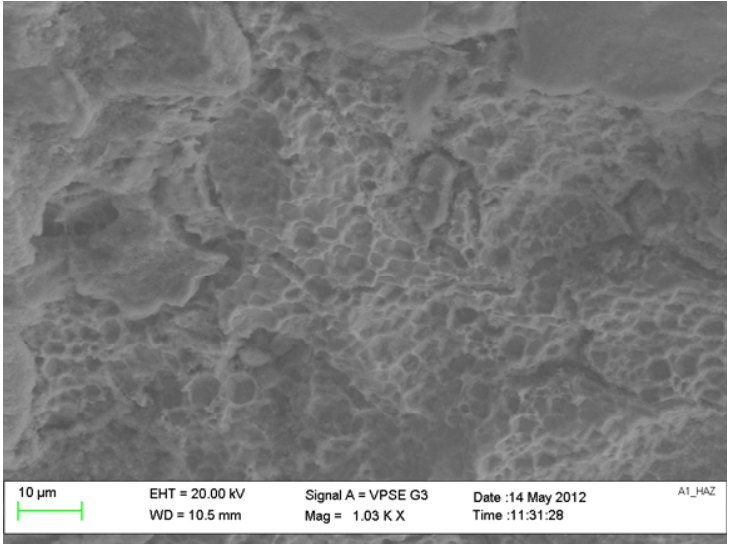

(b)

Figure 5. (a) Micrograph of the fusion zone for sample A1; (b) Micrograph of the heat affected zone for sample A1.

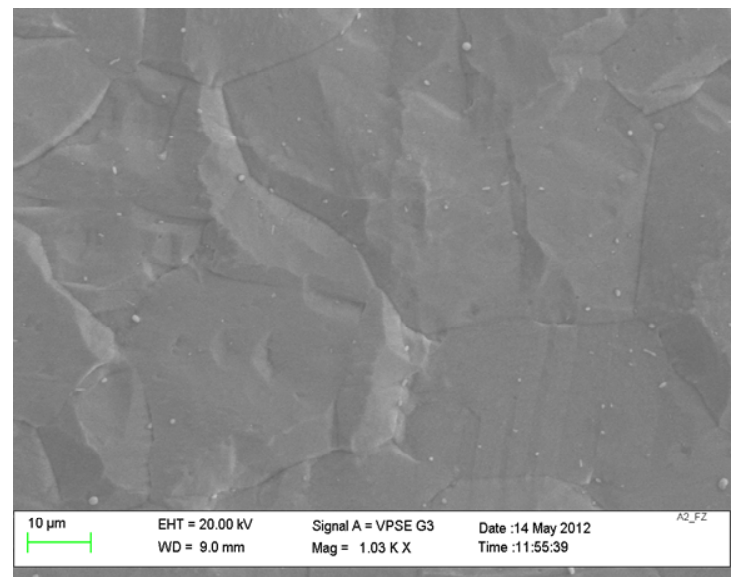

(a)

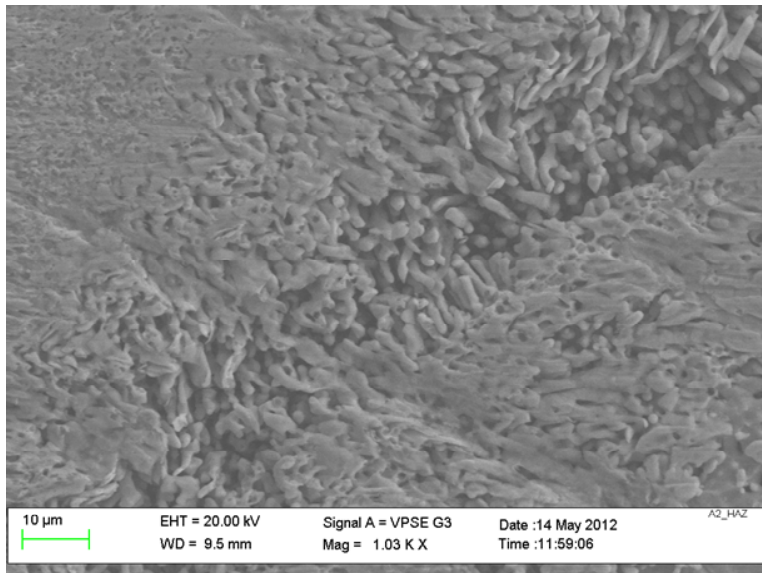

(b)

Figure 6. (a) Micrograph of the fusion zone for sample A2; (b) Micrograph of the heat affected zone for sample A2. 


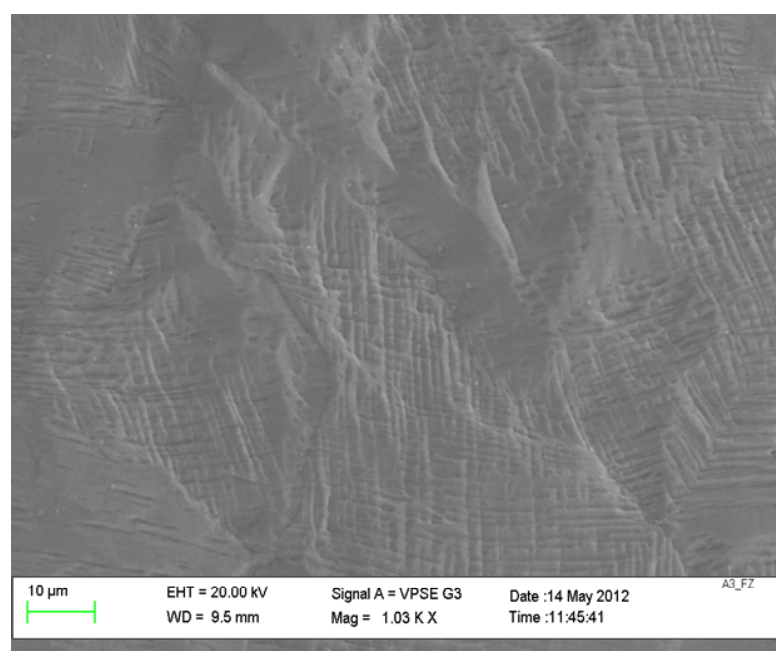

(a)

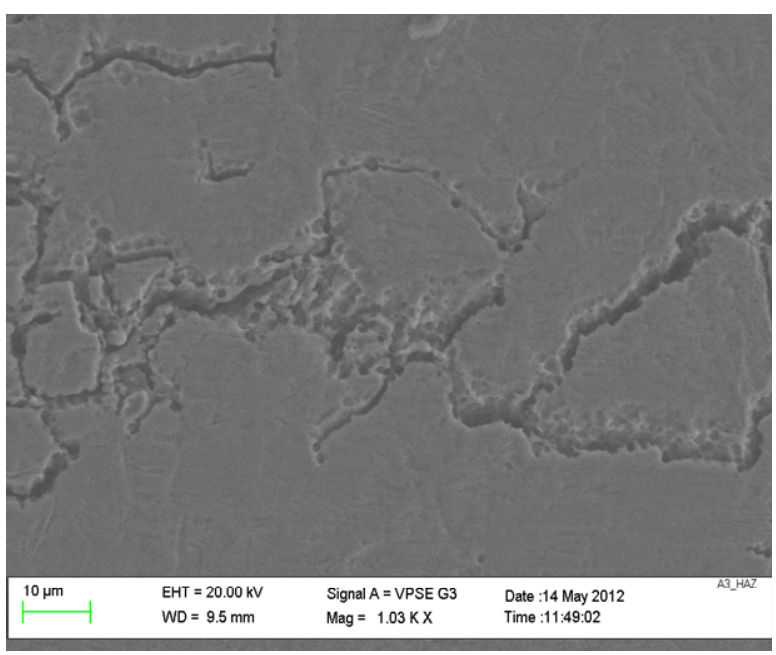

(b)

Figure 7. (a) Micrograph of the fusion zone for sample A3; (b) Micrograph of the heat affected zone for sample A3.

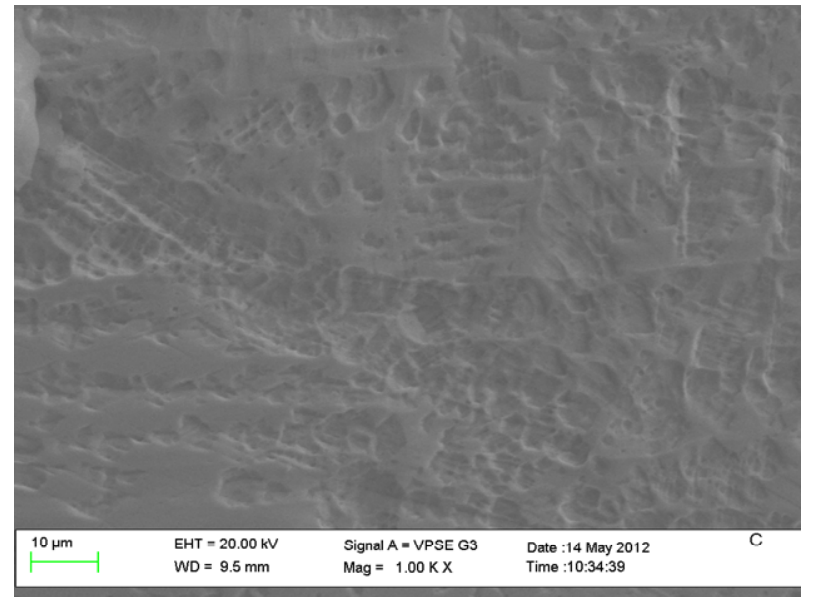

Figure 8. Micrograph for sample $\mathrm{C}$.

Morphological analysis using SEM clearly shows difference in the morphology of the heat affected zone and the parts that are not affected, causing the grains of the heat affected zone to be coarser than that of the unaffected zone (see Figure 4(b)). The microstructure clearly shows that there will be a great influence of this change in morphology to the properties of the welded samples.

The microstructure of the as received sample shows a fine grain boundary and an indication of a better blending of the parent material and the alloying elements (see Figure 8). From the SEM micrograph, there exist a variation in morphology of the fusion zone and heat affected zone for same sample. This is due to the difference in the cooling rate of the two zones (compare Figures 4(a) and (b), 5(a) and (b) etc.).

Finally, the grains sizes of the heat affected zone for samples A2 are shown to be finer as compared to other samples in the group. This is expected to give them better properties in their group. The basic information obtained from the SEM micrograph is in agreement with observations raised by other researchers [6-10], while the relationship between the microstructure and the properties of the developed composite agrees with conclusions of other researchers [11-14].

\subsection{Mechanical Properties of the Samples}

\section{Tensile Properties of the samples}

The results of the tensile tests carried out on the samples are recorded in Table 4 and Figure 4.

The comparison of the tensile strength for samples with the as received one is shown in Figure 9.

The comparison of the percentage elongation (Strain) for samples with the as received one is shown in Figure 10.

The results of the tensile test carried out on the samples, as recorded in Table 3 shows that, carrying out of post welding treatment increase the ductility of the samples, thereby making the materials to be tougher and decrease their tensile strength. The results also show that, treating the samples in lubricating oil after welding highly increases their ductility, making them to have highest elongation in their group. This can be associated to the fine grain size as revealed by the micrograph, compared to that of other samples in the group (see Figures 6(a) and (b)).

The results also shows that samples that underwent stress relief treatment after welding has higher tensile strength, next to those treated in lubricating oil, while those treated in neem oil has the lowest in their group. The results obtained from the tensile test of the material are in agreement with those obtained by other researchers [15-19].

\section{Impact Properties of the Samples}

The results of the impact test carried out on the sam- 
Table 4. The tensile tests results for samples. Area $A_{0}=7.85$ $\times 10^{-5}$ Gauge Length $I_{0}=50 \mathrm{~mm}$.

\begin{tabular}{ccccc}
\hline Sample & $\begin{array}{c}\text { Maximum Load } \\
(\mathrm{KN})\end{array}$ & $\begin{array}{c}\text { Tensile Strength } \\
\left(\mathrm{MN} / \mathrm{m}^{2}\right)\end{array}$ & $\begin{array}{c}\text { Elongation } \\
(\mathrm{mm})\end{array}$ & $\begin{array}{c}\text { Strain } \\
(\%)\end{array}$ \\
\hline $\mathrm{A}$ & 26.2 & 334 & 5.85 & 11.7 \\
$\mathrm{~A}_{1}$ & 17.4 & 222 & 6.65 & 13.3 \\
$\mathrm{~A}_{2}$ & 25.8 & 329 & 13.60 & 27.2 \\
$\mathrm{~A}_{3}$ & 26.0 & 331 & 6.57 & 18 \\
$\mathrm{C}$ & 79.6 & 1010 & 35.00 & 70 \\
\hline
\end{tabular}

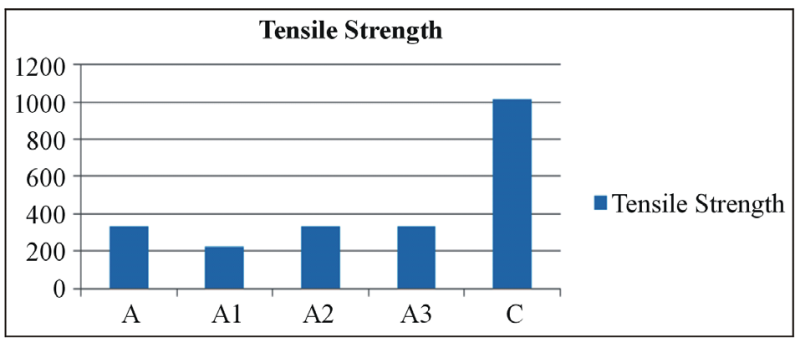

Figure 9. Tensile strength for group a as compared to Control.

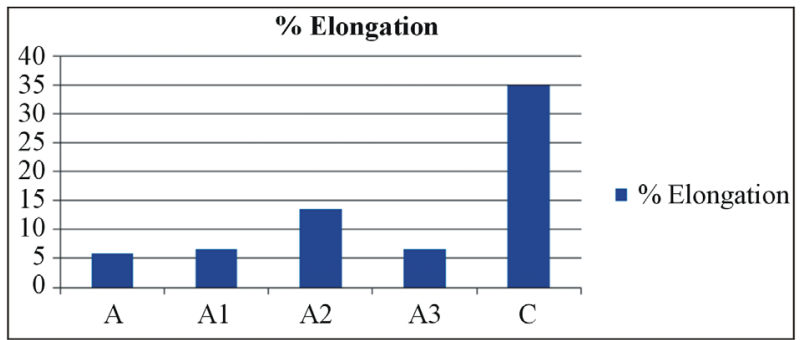

Figure 10. Percentage elongation for group a as compared to control.

ples are summarized in Table 5.

The comparison of the impact energy for group A samples with the as received one are shown in Figure 11 right.

The results of the impact test carried out on the samples as recorded in Table $\mathbf{5}$ show that the impact energy of the material rises from $38.64 \mathrm{~J}$ obtained in the non treated sample, as post weld treatment carried out on it to $56.2 \mathrm{~J}$ obtained in sample A2, which is the highest for group A, then fall to $51.86 \mathrm{~J}$ obtained in sample treated in neem oil. Also, the results show that samples that are welded without heat treatment absorb less impact energy than those welded and heat treated. The variation in the impact test results is in agreement with variation of their elongation at failure during tensile test. The variation in the impact energy of the samples also agrees with observations made by other researcher [20-24].

Rockwell Hardness Number for the Samples

The results of the hardness test carried out on the samples are summarized in Table 6.
The comparison of the hardness number for group A samples with the as received one is shown in Figure 12 below.

The results obtained from the hardness test show that the hardness numbers of the treated samples differ from those obtained from samples that are not treated, depending on the kind of treatment carried out on them (see

Table 5. The impact tests results for samples.

\begin{tabular}{ccc}
\hline Sample & Average energy (ft pound) & Average energy joules (J) \\
\hline $\mathrm{A}$ & 28.50 & 38.64 \\
$\mathrm{~A}_{1}$ & 40.25 & 54.57 \\
$\mathrm{~A}_{2}$ & 41.45 & 56.20 \\
$\mathrm{~A}_{3}$ & 38.25 & 51.86 \\
$\mathrm{C}$ & 120.00 & 62.70 \\
\hline
\end{tabular}

Table 6. Rockwell hardness number for the samples.

\begin{tabular}{ccc}
\hline Sample & $\begin{array}{c}\text { Hardness value (HRA) } \\
\text { Fusion zone }\end{array}$ & $\begin{array}{c}\text { Hardness value (HRA) } \\
\text { Heat affected zone }\end{array}$ \\
\hline $\mathrm{A}$ & 49.9 & 63.1 \\
$\mathrm{~A}_{1}$ & 46.0 & 57.3 \\
$\mathrm{~A}_{2}$ & 44.4 & 56.5 \\
$\mathrm{~A}_{3}$ & 49.5 & 60.3 \\
$\mathrm{C}$ & 65.8 & \\
\hline
\end{tabular}

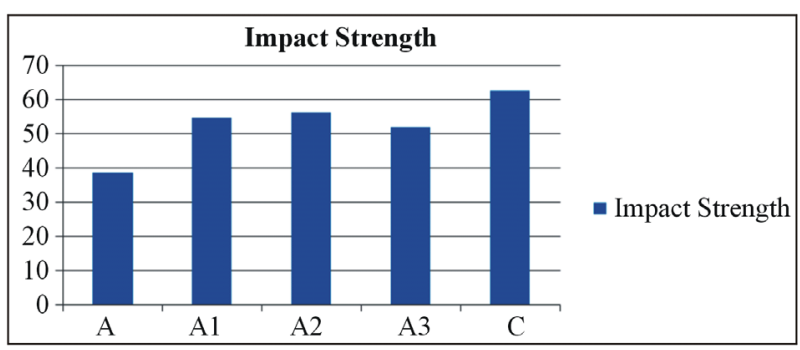

Figure 11. Impact energy for group A as compared to control.

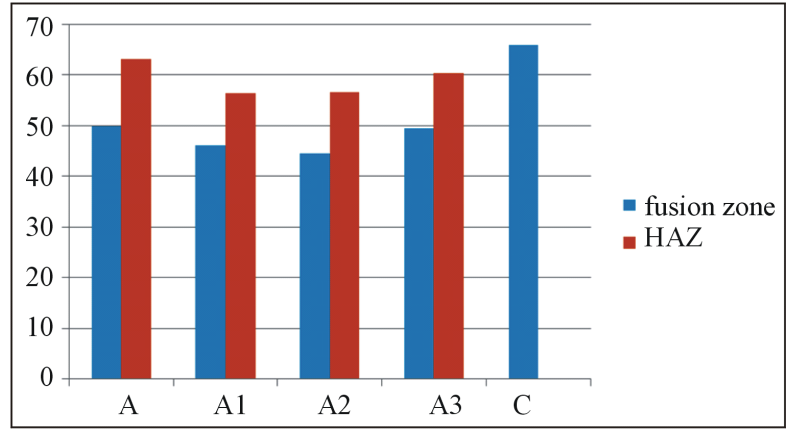

Figure 12. Hardness number for group $A$ as compared to control. 
Figure 12). The hardness number of samples that are treated in lubricating oil is lower as compared to other treated samples in their group. This is expected since the softer a material the higher its ductility thus its toughness. The result also implies that treating the welded samples in lubricating oil increases their ductility and decreases their hardness.

The variation in the hardness number of the samples also agrees with observations made by other researchers $[3,20-25]$.

\section{Conclusions}

1) The duplex stainless steel can be welded successfully using gas metal arc welding process depending on the application or service life which the material will be subjected to.

2) Both lubricating oil and neem oil can serve as quenching medium for post weld treatment of duplex stainless steel. But lubricating oil gives better results compared to neem oil in terms of toughness, elongation.

3) Tempering after quenching improved the mechanical properties of the alloy.

The tensile test, impact test and the hardness test shows that welding has a negative effect on the mechanical properties of this alloy.

\section{REFERENCES}

[1] A. K. Bhaduri, S. K. Albert, S. K. Ray and Rodriguez, "Recent Trends in Repair and Refubishing of Steam Turbine Component," Sahdhana, Vol. 24, No. 3 \& 4, 2003, pp. 395-408. doi:10.1007/BF02706440

[2] "Duplex Stainless Steel," 2011. http://www.weldingengineer.com

[3] E. T. Dauda, "Weldability Assessment of Some Locally Sourced Steels," PhD Dissertation Department of Metallurgical Engineering A. B. U, Zaria, 2008.

[4] T. Roger and M. Tony, "Newnes Mechanical Engineer's Pocket Book," CBS Publishers and Distributors, New Delhi, 1999.

[5] Atlas Steels Australia, "Stainless Steels," 2011. www.azom.com/materials

[6] R. Gunn, "Duplex Stainless Steels-Microstructure, Properties and Applications," Abington Publishing, Cambridge, 1997. doi:10.1533/9781845698775

[7] P. Claes-Ove and F. Sven-Áven, "Welding Practice for the Sandvik Duplex Stainless Steels SAF 2304, SAF2205 and SAF2507," AB Sandvik Steel, S-811 81 Sandviken, 1995.

[8] P. K. Rohatgi, F. M. Yarandi and Y. Liu, "Proceedings of International Symposium on Advances in Cast Reinforced Metal Composites," In: S. G. Fishman and A. K. Dhingra, Eds., ASM International Publication, Materials Park, 249, 1998.

[9] A. F. Whitehouse, R. A. Shahani and T. W. Clyne, "Me- tal Matrix Composites: Processing, Microstructure and Properties," In: R. N. Hansen et al., Eds., 12 Ris $\theta$ International Symposium, Ris $\theta$ National Laboratory, Denmark, 1991, pp. 741-748.

[10] W. Zhou and Z. M. Xu, "Casting of SiC Reinforced Metal Matrix," Journal of Materials Processing Technology, Vol. 63, No. 1-3, 1997, pp. 358-363. doi:10.1016/S0924-0136(96)02647-7

[11] L. A. Pothan, S. Thomas and Neelakantan, "Short Banana Fiber Reinforced Polyester Composites, Mechanical, Failure and Aging Characteristics," Journal of Reinforced Plastics and Composites, Vol. 16, No. 8, 1997, pp. 744765.

[12] S. J. He, K. Y. Shi, J. Bai, Z. K. Zhang, L. Li, Z. J. Du and B. L. Zhang, "Studies on the Properties of Epoxy Resins Modified with Chain-Extended Ureas," Journal of Polymer, Vol. 42, No. 23, 2001, pp. 9641-9647. doi:10.1016/S0032-3861(01)00450-5

[13] I. A. Madugu, M. Abdulwahab and V. S. Aigbodion, "Effect of Iron Filings on the Properties and Microstructure of Cast Fibre-Polyester/Iron Filings Particulate Composite," Journal of Alloys and Compound, Vol. 476, No. 1-2, 2010, pp. 808-811.

[14] A. K. Mohanty, M. Misra and L. T. Drzal, "Sustainable BioComposites from Renewable Resource," Opportunity and Challenges in the Green Materials World, Journal of Polymer and Environment, Vol. 10, No. 1-2, 2002, pp. 19-26.

[15] R. Asthana, "Solidification Processing of Reinforced Metals," Transport Technology Publications, 1998, pp. 6780.

[16] T. W. Clyne, "Comprehensive Composite Materials," Journal of Metal Matrix Composite, Vol. 3, 2000, pp. 1-8.

[17] S. Donne, M. R. Krishnadev and R. Bouchard, "Metal and Ceramic Matrix Mechanical Behavior," The Minerals Metals and Materials Society, 1990, pp. 243-251.

[18] A. Sagail and G. Leisk, "Heat Treatment Optimization of Alumina/Aluminium Metal Matrix Composites Using the Taguchi Approach," Journal of Scripta Metallurgica et Material, Vol. 26, No. 6, 1992, pp. 871-876.

[19] Y. Sukru, O. Cavdar and A. Cavdar, "The Effects of the Fibre Contents on the Mechanical Properties of the Adobes," Journal of Construction and Building Materials, Vol. 22, No. 3, 2008, pp. 222-227. doi:10.1016/j.conbuildmat.2006.08.022

[20] J. P. Cottu, J. J. Coudere, B. Viguier and L. Bernard, "Influence of SiC Reinforcement on Precipitation and Hardening of a Metal Matrix Composite," Journal of Material Science, Vol. 27, No. 11, 1992, pp. 3068-3074. doi:10.1007/BF01154120

[21] J. W. Kock, "Physical and Mechanical Properties of Chicken Feather Materials," Msc Thesis Presented to the Academic Faculty Georgia Institute of Technology, 2000.

[22] S. C. Mishra, N. B. Nayak and A. Satapathy, "Investigation on Bio-Waste Reinforced Epoxy Composites," Metallurgical and Materials Engineering Department, National Institute of Technology, Rourkela, 1999, pp. 119-123.

[23] N. M. White and M. P. Ansell, "Straw Reinforced Poly- 
ester Composites," Journal of Material Science, Vol. 18, No. 5, 1993, pp. 1549-1556. doi:10.1007/BF01111977

[24] J. Nowacki and P. Rybicki, "Corrosion Resistance of SAW Duplex Joints Welded with High Heat Input," Journal of Achievements in Materials and Manufacturing Engineering, Vol. 23, No. 2, 2007, pp. 7-14.
[25] J. Labanowski and K. Krzysztofowicz, "The Influence of Welding Thermal Cycles on Corrosion Resistance of Duplex Stainless Steel," 2005.

www.pg.gda.pl/mech/kim/AMS/022005/ams02200503.pd f 